Check for updates

Cite this: RSC Adv., 2017, 7, 26689

Received 27th February 2017

Accepted 29th April 2017

DOI: $10.1039 / \mathrm{c} 7 \mathrm{ra0} 2415 \mathrm{k}$

rsc.li/rsc-advances

\section{ZnO films using a precursor solution irradiated with an electron beam as the cathode interfacial layer in inverted polymer solar cells $\uparrow$}

\author{
Rira Kang, ${ }^{a}$ Yong-Jin Noh, ${ }^{b}$ Jin-Mun Yun, ${ }^{a}$ Hyun Kim, ${ }^{a}$ NoSoung Myoung, ${ }^{d}$ \\ Eun-Hye Lee, ${ }^{c}$ Tae-Wook Kim, (D) ${ }^{c}$ Seok-In Na (D) ${ }^{* b}$ and Seung-Hwan Oh iD t $^{* a}$
}

\begin{abstract}
We demonstrate the possibility of irradiating sol-gel $\mathrm{ZnO}$ with an electron beam (EB-ZnO) to modify solgel $\mathrm{ZnO}$, and EB-ZnO is explored as a cathode interfacial layer for inverted polymer solar cells. We investigate the effect of EB-ZnO on the surface, optical and electric properties of sol-gel ZnO films through morphology, chemical composition, optical band gap shift, various defect excitations (photoluminescence) and work function measurement. Oxygen vacancies and the formation of nitrogen on the surface of EB-ZnO films contribute to the formation of $n$-type degenerated EB-ZnO films. The electric properties of EB-ZnO strongly depend on the adsorbed dose, and EB-ZnO with a suitable dose of $100 \mathrm{kGy}$ improved the power conversion efficiency of inverted polymer solar cells based on PTB7-Th: $\mathrm{PC}_{71} \mathrm{BM}$ from $8.05 \%$ for non-treated sol-gel $\mathrm{ZnO}$ to $9.36 \%$ for $\mathrm{EB}-\mathrm{ZnO}$ with an enhanced fill factor.
\end{abstract}

\section{Introduction}

Polymer solar cells (PSCs) have attracted considerable attention due to their low cost, light weight, flexibility, environmentally friendly energy sources. ${ }^{1-7}$ Various strategies (low band gap donors, ${ }^{\mathbf{1 , 2}}$ novel acceptors, ${ }^{3,4}$ new device configurations, ${ }^{5,6}$ and interface engineering ${ }^{7,8}$ ) have been rapidly developed to improve their power conversion efficiency (PCE). Recently, PSCs with low band gap donors have achieved PCE greater than $10 \% .^{\mathbf{1 , 2}}$ The inverted device configuration in polymer solar cells (ITO/cathode interfacial layer/active layer/anode interfacial layer/Ag) has been widely used due to its higher PCEs and longer lifetimes than that of the conventional configuration. ${ }^{9}$

In inverted PSCs, a cathode interfacial layer (CIL) such as metal oxide $\left(\mathrm{ZnO}, \mathrm{TiO}_{x}\right.$ and $\left.\mathrm{Cs}_{2} \mathrm{CO}_{3}\right)$ and conjugated polymers is required to change the polarity of ITO to a cathode., ${ }^{7,10,11}$ Among them, sol-gel ZnO has been the most commonly used material

\footnotetext{
${ }^{a}$ Radiation Research Division for Industry and Environment, Korea Atomic Energy Research Institute (KAERI), 29 Geumgu-gil, Jeongeup-si, Jeollabuk-do 580-185, Republic of Korea. E-mail: ohsh@kaeri.re.kr

${ }^{b}$ Professional Graduate School of Flexible and Printable Electronics, Polymer Materials Fusion Research Center, Chonbuk National University, 664-14, Deokjin-dong, Jeonjusi, Jeollabuk-do 561-756, Republic of Korea.E-mail: nsi12@jbnu.ac.kr

${ }^{c}$ Advanced Photonics Research Institute (APRI), Gwangju Institute of Science and Technology (GIST), Gwangju 61005, Republic of Korea

${ }^{d}$ Soft Innovative Materials Research Center, Institute of Advanced Composite Materials, Korea Institute of Science and Technology, Joellabuk-do 565-905, Republic of Korea

$\dagger$ Electronic supplementary information (ESI) available. See DOI: 10.1039/c7ra02415k

\$ These two authors are contributed equally to this work.
}

as a CIL due to its (1) high transparency, (2) suitable energy level (conduction band: $-4.4 \mathrm{eV}$ and valence band: $-7.8 \mathrm{eV}$ ) for electron collection and hole blocking, (3) good electron mobility, and (4) easy solution processing. ${ }^{\text {10-12 }}$ However, the widely used sol-gel ZnO exhibits many surface defects/traps, such as dangling bonds and adsorbed oxygen on its surface due to low temperature solution processing. ${ }^{11}$ Such defects act as recombination centers and lead to poor device performances in PSCs. To overcome these problems, many approaches such as control of morphology, modification of nanostructure, doping and surface modification with self-assembly layer or polymers bilayer have been developed for better electron collection. ${ }^{\mathbf{1 0 - 1 2}}$

As a promising new approach, techniques based on various types of ionizing radiation (alpha, electron beam, gamma rays, $\mathrm{X}$-rays, laser ablation, $\alpha$-particles, neutrons, protons, and ion beams) for the fabrication and synthesis of materials are becoming useful. ${ }^{\mathbf{1 3 , 1 4}}$ The high energy of electron beam leads to the formation of radicals within a short time. ${ }^{14}$ Especially, the effect of electron-beam irradiation on the electrical and optical properties of ZnO was recently investigated. K. P. Sapnar et al. synthesized ZnO nanoparticles (NPs) via microwave, and the ZnO NPs powder was exposed to electron irradiation, which resulted in an increase in their bandgap and reduction of the NPs size. ${ }^{15} \mathrm{~J}$. S. Bhat et al. observed an increase in sheet resistance, blue shift in the absorption edge and decrease in structural homogeneity and crystalline size after sol-gel ZnO and ZnO:Al films were exposed to electron irradiation. ${ }^{\mathbf{1 6}}$ The results of such research indicate that electron beam irradiation could induce defects and modify electronic and optical properties, regardless of the phase of $\mathrm{ZnO}$ (films or powder). However, to the best of our knowledge, the application of $\mathrm{ZnO}$ 
exposed to electron irradiation in solar cells has not yet been reported.

Hence, sol-gel $\mathrm{ZnO}$ irradiated with an electron beam was developed as a CIL in inverted polymer solar cells with a device structure of ITO/electron-beam based sol-gel ZnO (EB-ZnO)/ PTB7-Th: $\mathrm{PC}_{71} \mathrm{BM} / \mathrm{MoO}_{3} / \mathrm{Ag}$. Herein, the application of EB-ZnO as a cathode interfacial in PSCs is first reported. We directly irradiate the sol-gel $\mathrm{ZnO}$ precursor solution with an electron beam as a function of adsorbed dose (100, 300 and $500 \mathrm{kGy}$ ), and use $\mathrm{ZnO}$ films spin-coated from the irradiated solution as a CIL in inverted PSCs. This electron irradiation makes the solgel $\mathrm{ZnO}$ n-type degenerated by inducing oxygen vacancies, which can increase electron concentrations; and their surface composition, morphology, photoluminescence, energy-level diagram are investigated to understand the fundamentals of the changed properties of EB-ZnO. The inverted PSCs with EBZnO at $100 \mathrm{kGy}$ exhibit the best power conversion efficiency (PCE) of $9.36 \%$ due to the enhanced fill factor of $71.8 \%$. In addition, the device with EB-ZnO at $100 \mathrm{kGy}$ exhibits the lowest series resistance and dominant bimolecular recombination.

\section{Experimental}

Preparation of irradiated sol-gel ZnO with electron beam (EBZnO)

Sol-gel ZnO was prepared according to a previous report. ${ }^{17} \mathrm{Next}$, $20 \mathrm{~mL}$ sol-gel $\mathrm{ZnO}$ in a glass vial was irradiated at room temperature with electron-beam irradiation at a scan rate of 10 kGy $\min ^{-1}$ created by $2.5 \mathrm{MeV}$ UELV-10-10S electron accelerator at the Korea Atomic Energy Research Institute (ex. 2.5 MeV $\times 5.8$ $\mathrm{mA} \times 10 \mathrm{~m} \mathrm{~min}^{-1} \times 1$ turn $=10 \mathrm{kGy}$ ). The total absorbed doses were 100, 300 and $500 \mathrm{kGy}$. The untreated sol-gel $\mathrm{ZnO}$ and solgel $\mathrm{ZnO}$ irradiated with electron beam at 100, 300 and $500 \mathrm{kGy}$ are denoted as Ref, EB-Z100, EB-Z300 and EB-Z500, respectively.

\section{Fabrication and characterization of inverted polymer solar cells}

To fabricate the device, ITO coated glass was cleaned with acetone, DI water and IPA, dried in an oven, and UV-ozone treated for $20 \mathrm{~min}$. EB-ZnO was spin-coated onto ITO, at a thickness of $\sim 60 \mathrm{~nm}$, followed by drying at $150{ }^{\circ} \mathrm{C}$ for $30 \mathrm{~min}$ under air. As the active layer, a blend solution film of $12 \mathrm{mg}$ of PTB7-Th (1-material) and $18 \mathrm{mg}$ of $\mathrm{PC}_{71} \mathrm{BM}$ (1-material) in $1 \mathrm{~mL}$ of chlorobenzene with $5 \%(\mathrm{v} / \mathrm{v})$ the additive DIO was then spincoated onto EB-ZnO at $2000 \mathrm{rpm}$ for $60 \mathrm{~s}$ in an $\mathrm{N}_{2}$-filled glove box. Under the vacuum of $10^{-6}$ torr, $3 \mathrm{~nm} \mathrm{MoO}_{3}$ was thermally evaporated onto the active layer, and then $80 \mathrm{~nm}$-thick silver as the anode electrode was thermally deposited onto $\mathrm{MoO}_{3}$ through a shadow mask with an area of $4.64 \mathrm{~mm}^{2}$. The photocurrent-voltage $(J-V)$ characteristics of the devices were measured using a Keithley 2400 instrument and solar simulator (Oriel sol3A) under air.

\section{Sample characterization}

Atomic force microscopy (AFM) (Veeco, Digital Instruments Nanoscope IIIA) in tapping mode was used to characterize the
EB-ZnO films spin-coated on Si wafers. X-ray photoelectron spectroscopy (XPS) and ultraviolet photoemission spectroscopy (UPS) measurements (AXIS NOVA, Kratos) were carried out for the EB-ZnO films spin-coated on ITO substrates (monochromatized $\mathrm{Al} \mathrm{K} \alpha$ for XPS, and a $\mathrm{He} \mathrm{l}(h \nu=21.2 \mathrm{eV})$ excitation for UPS at a pressure of $5 \times 10^{-8}$ torr). The UV-vis spectra of spin-coated EB-ZnO films spin-coated on glass substrates were recorded using a spectrophotometer. Photoluminescence (PL) spectra of EB-ZnO films spin-coated on glass substrates were measured via the $2^{\text {nd }}$ harmonic generation (at $350 \mathrm{~nm}$ ) of a mode-locked Ti:Sapphire laser (Chameleon Ultra II coherent) at $300 \mathrm{~K}$. Transmission electron microscopy (TEM) was used to investigate the crystalline size of EB-ZnO (Titan 80-300, FEI, operated at $300 \mathrm{kV}$ ). For the characterization, the EB-ZnO films were prepared via the same procedures as that for device fabrication.

\section{Result and discussion}

\section{Surface properties}

Fig. 1a shows a photograph of the actual solutions of Ref, EBZ100, EB-Z300 and EB-Z500. With an increase in the adsorbed dose from 100 to $500 \mathrm{kGy}$, the color of the EB-ZnO solution changed from transparent to orange-red. To observe the differences in surface properties between all the samples, as shown in Fig. 1b, the morphologies of the Ref and EB-ZnO samples were investigated via atomic force microscopy (AFM). All the samples exhibit flat surfaces without a ripple type morphology, which is probably due to the low-temperature annealing. EB-Z100 a slightly reduced surface roughness compared with that of Ref; whereas EB-Z500 shows a rough surface with a random distribution of particles. The increase in surface roughness suggests that electrons cannot be collected beneficially to the cathode. To observe the change in the crystalline size of EB-ZnO, the EB-ZnO samples were characterized using TEM. Unexpectedly, there was no significant change in all the samples (crystalline size: about $0.23 \mathrm{~nm}$ in Fig. S1†).

In order to obtain information about the surface of EB-ZnO, XPS analysis was carried out on EB-ZnO. The binding energies were calibrated with respect to the $\mathrm{C} 1 \mathrm{~s}$ peak at $258.0 \mathrm{eV}$. As

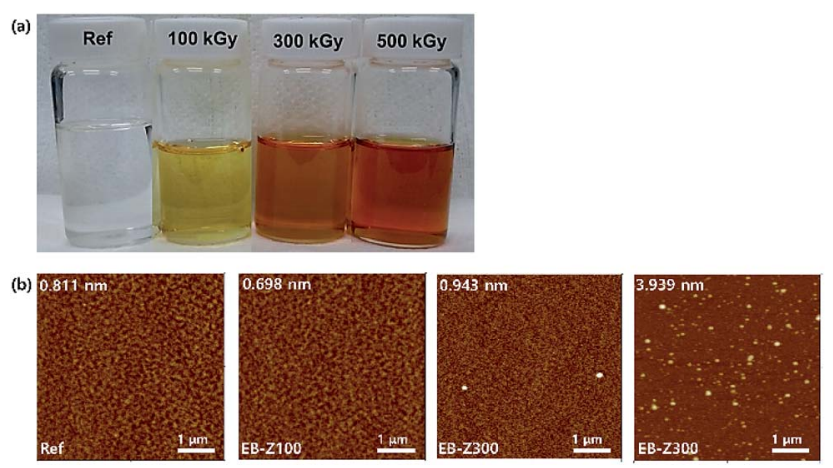

Fig. 1 (a) Photograph of the Ref and EB-ZnO precursor solutions and (b) AFM images of the Ref and EB-ZnO films with a size of $5 \times 5 \mu \mathrm{m}^{2}$. The upper left value is the root-mean-square (RMS) in the AFM images. 
shown in Fig. 2, the $\mathrm{O}$ 1s peaks can be deconvoluted into three Gaussian components $\left(\mathrm{O}_{\mathrm{a}}: \mathrm{O}^{2-}\right.$ ions in the $\mathrm{ZnO}$ lattice, $\mathrm{O}_{\mathrm{b}}: \mathrm{O}^{2-}$ ions in the oxygen vacancy of $\mathrm{ZnO}$ and $\mathrm{O}_{\mathrm{c}}$ : chemisorbed oxygen species on the surface of $\mathrm{ZnO}) .{ }^{18}$ For better comparison, the content and peak positions of each $\mathrm{O} 1 \mathrm{~s}$ component are shown in Fig. 2. The $\mathrm{O} 1 \mathrm{~s}$ peaks of Ref are centered at $530.6 \mathrm{eV}\left(\mathrm{O}_{\mathrm{a}}\right.$ : $63.8 \%), 531.5 \mathrm{eV}\left(\mathrm{O}_{\mathrm{b}}: 7.7 \%\right)$ and $531.9 \mathrm{eV}\left(\mathrm{O}_{\mathrm{c}}: 28.5 \%\right)$. With the increase in the irradiation dose, the $\mathrm{O} 1 \mathrm{~s}$ peaks broaden and shift toward lower binding energies by $0.4,0.9$ and $0.7 \mathrm{eV}$, and the content of $\mathrm{O}_{\mathrm{b}}$ increases to $43.3 \%, 80.1 \%$ and $58.0 \%$ for EBZ100, EB-Z300 and EB-Z500, respectively. It is known that such oxygen vacancy can act as donors, which lead to degenerate $\mathrm{ZnO}$ by increasing the electron carrier density in the conduction band (CB) of $\mathrm{ZnO}$. Moreover, the content of $\mathrm{O}_{\mathrm{c}}$ decreases to $12.0 \%, 1.3 \%$ and $1.9 \%$ for EB-Z100, EB-Z300 and EB-Z500, respectively. The surface hydroxyl groups trap photoinduced electrons and holes, thus enhancing the photocatalytic degradation process. It is noted that electron beam irradiation can induce oxygen vacancies and reduce surface hydroxyl groups of sol-gel ZnO. ${ }^{34}$

For all samples, $\mathrm{Zn} 2 \mathrm{p}$ has doublet peaks (for the non-treated

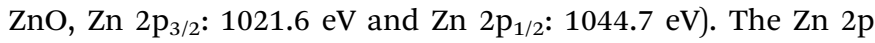
peak shifts toward a lower binding energy by $0.4,0.7$ and $0.8 \mathrm{eV}$ for EB-Z100, EB-Z300 and EB-Z500, respectively, similarly to the shift of the $\mathrm{O}$ 1s peak. FWHM (full width at half maximum) can be an indicator of chemical state changes and physical influence. With the increase in irradiation dose, Zn 2p FWHM broadening occurs (Ref: 1.456, EB-Z100: 1.497, EB-Z300: 1.551 and EB-Z500: 1.776), and additional peaks are also observed at higher biding energies (the shaded area of the insets in Fig. 2). This result can be attributed to the presence of zinc interstitial $\left(\mathrm{Zn}_{\mathrm{i}}\right){ }^{19}$ It is reported that $\mathrm{Zn}_{\mathrm{i}}$ can degenerate $\mathrm{ZnO}$ by acting as donors and can interact with adjacent active layers with respect to the stability of polymer solar cells. ${ }^{35}$
Interestingly, we also observed $\mathrm{N}$ 1s spectra in the EB-ZnO samples, but not in Ref. The N 1s of EB-Z100 can be deconvoluted into two peaks at 398.1 and $399.7 \mathrm{eV}$, which are attributed to $-\mathrm{C}=\mathrm{N}-$ and $-\mathrm{NH}-\mathrm{C}$ or $\mathrm{N}-(\mathrm{C})_{3}$, respectively. ${ }^{20}$ Given the content of $\mathrm{O}_{\mathrm{b}}$ for the EB-ZnO samples, it is expected that $\mathrm{N}$ atoms do not occupy the $\mathrm{O}$ sites in our study (i.e., $\mathrm{N}-\mathrm{Zn}$ bonds is not observed). The two peaks of EB-Z300 and EB-Z500 slightly shift toward lower binding energies, which contributes to the enhanced electron concentration of the modified EB-ZnO surface by the interaction between different types of amines and $\mathrm{ZnO}$. Although the origin of $\mathrm{N}$ formation on the EB-ZnO surface is not clear, it can originate from the byproduct $\left(\mathrm{NH}_{4}{ }^{+}\right)$related to the degradation of ethanolamine ${ }^{21}$ or unstable intermediate products such as $\mathrm{OH}^{*}$ and $\mathrm{H}^{*}$ radicals by electron beam irradiation. ${ }^{13}$ It can be suggested that the byproducts, unstable intermediate products and reactants from the $\mathrm{ZnO}$ precursor solution, which are not volatile at $150{ }^{\circ} \mathrm{C}$, are adsorbed on the surface of $\mathrm{ZnO}$.

\section{Optical properties}

The optical properties of the samples were investigated, as shown in Fig. 3a and b. The band gaps $\left(E_{\mathrm{g}}\right)$ of EB-ZnO were estimated from the $(\alpha h \nu)^{2} v s$. $h v$ plot (Tauc plot extrapolation). The band gap is estimated to be 3.33, 3.36, 3.38 and $3.37 \mathrm{eV}$ for Ref, EB-Z100, EB-Z300 and EB-Z500, respectively (refer to Table 2 and Fig. 2a). The absorption spectra of samples are presented in Fig. 2b. All the EB-ZnO samples show UV absorption and transparency in the visible region and with the increase in absorption dose, their band gaps increase. The EB-Z500 sample is significantly blue shifted compared to the other samples. The band gap widening of the EB-ZnO samples is probably due to the well-known Burstein-Moss effect (BM effect), which is related to heavily doped/degenerated semiconductors. The BM
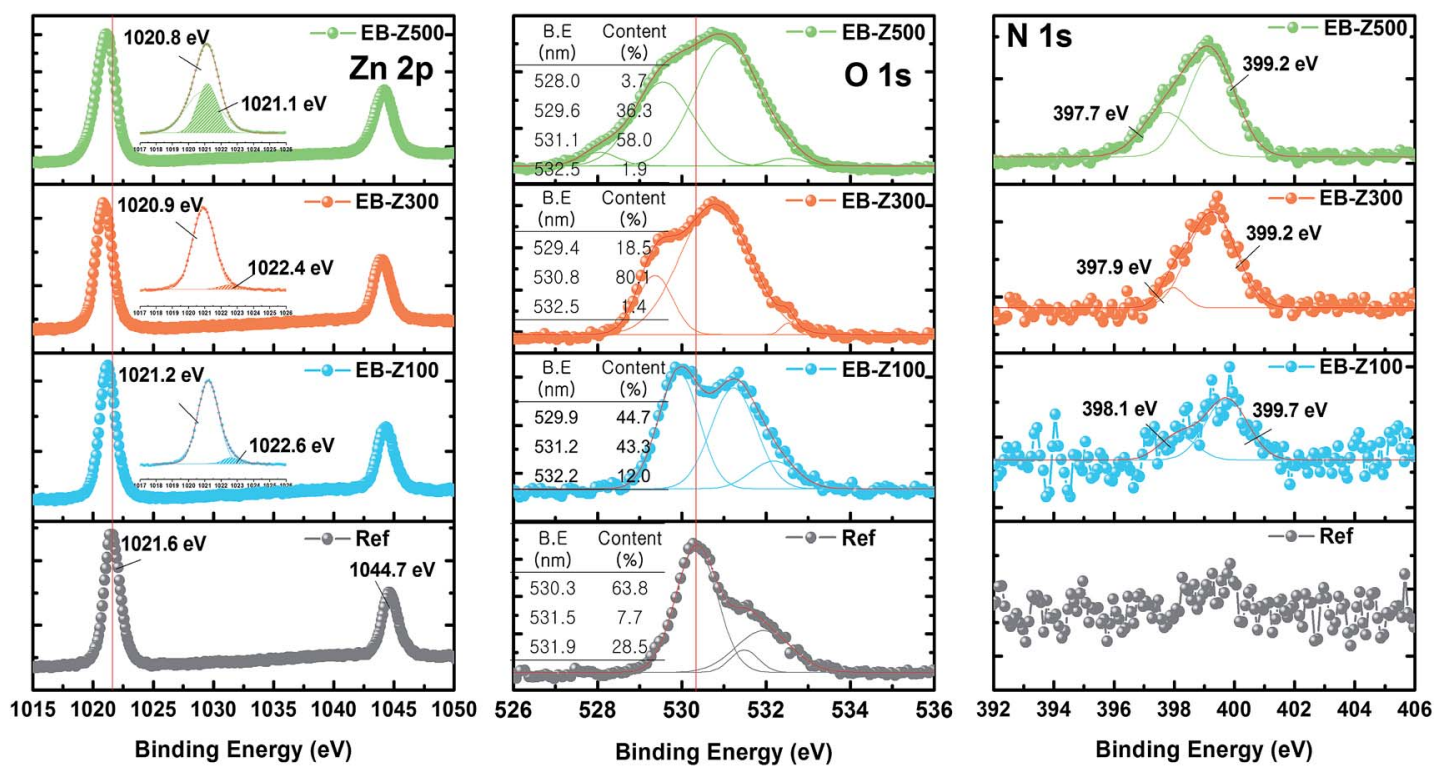

Fig. 2 Zn 2p, O 1s, and N 1s XPS spectra of Ref, EB-Z100, EB-Z300 and EB-Z500 (inset in the O 1s XPS spectra is the content of oxygen species calculated from $\mathrm{O}$ 1s fitting spectra). 
(a)

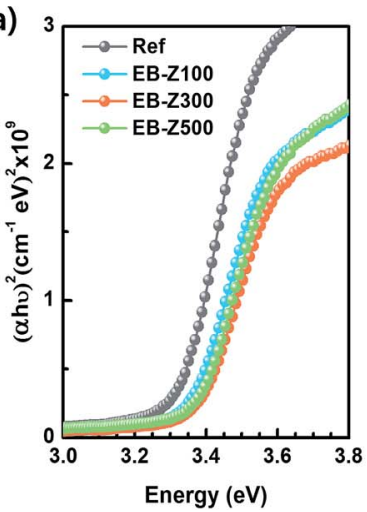

(b)

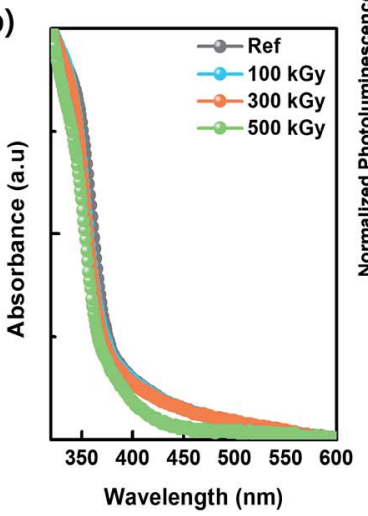

$\begin{array}{llllllllllllllll}350 & 400 & 450 & 500 & 550 & 600 & 650 & 700 & 350 & 400 & 450 & 500 & 550 & 600 & 650 & 700\end{array}$

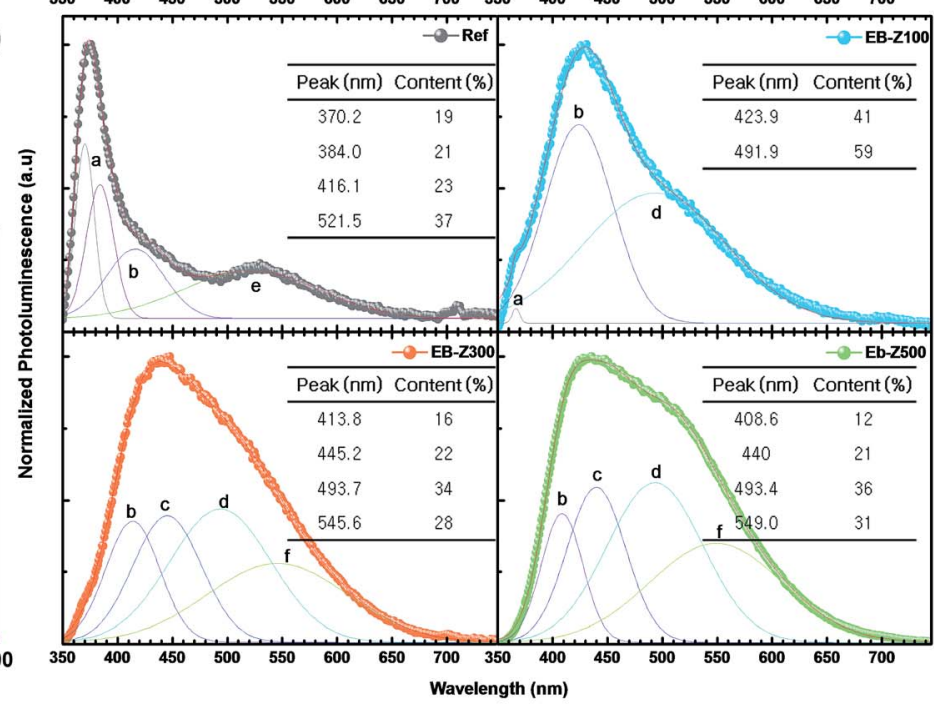

Fig. 3 (a) Tauc plot, (b) UV-vis spectra and (c) normalized photoluminescence (PL) spectra of Ref, EB-Z100, EB-Z300 and EB-Z500. PL spectra were deconvoluted into Gaussian peaks (a to f correspond to Table 1 and Scheme 1).

Table 1 The spectral locations of the deconvoluted peaks and their possible emission mechanism

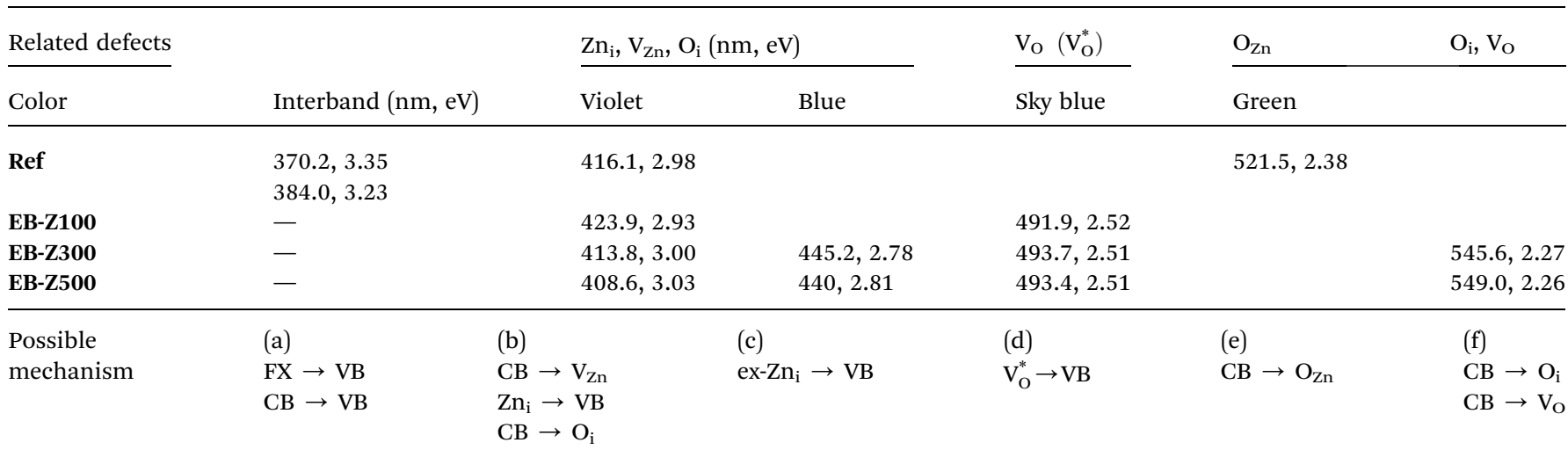

effect is the phenomenon in which doping causes a Fermi level $\left(E_{\mathrm{f}}\right)$ shift above the conduction band, i.e. since electrons fill up all the states below $E_{\mathrm{f}}$, the optical band gap increases. ${ }^{22,23}$

In addition, for the characterization of EB-ZnO defects, the photoluminescence (PL) spectra of samples are shown in Fig. 3c. The Ref sample shows both UV emission and visible emission and EB-Z100 slightly shows UV emission, whereas the other EB-ZnO samples did not show UV emission (red-shifted PL) despite their blue-shifted UV-vis spectra. Such red-shifted PL spectra of EB-ZnO result from the fact that absorption occurs from the valance band to the $E_{\mathrm{f}}$ or the conduction band (CB), whereas luminescence occurs from the impurity-donor band to the valance band (VB) or acceptor-like state. ${ }^{24}$ Since PL spectra are suitable tools for the characterization of the defects, the PL spectra were deconvoluted into several Gaussian subpeaks. Generally, there are a number of defect states within the bandgap of $\mathrm{ZnO}$ (donor defects: zinc interstitial, $\mathrm{Zn}_{\mathrm{i}}$, and oxygen vacancy, $\mathrm{V}_{\mathrm{O}}$, acceptor defects: zinc vacancy, $\mathrm{V}_{\mathrm{Zn}}$, oxygen
Table 2 The bandgap, valence band, conduction band and work function of values Ref, EB-Z100, EB-Z300 and EB-Z500

\begin{tabular}{lllll}
\hline & $E_{\mathrm{g}}(\mathrm{eV})$ & V.B $(\mathrm{eV})$ & C.B $(\mathrm{eV})$ & W.F $(\mathrm{eV})$ \\
\hline Ref & 3.33 & 7.56 & 4.23 & 4.12 \\
EB-Z100 & 3.35 & 7.54 & 4.19 & 3.75 \\
EB-Z300 & 3.38 & 7.44 & 4.06 & 3.55 \\
EB-Z500 & 3.37 & 7.44 & 4.07 & 2.99
\end{tabular}

interstitial, $\mathrm{O}_{\mathrm{i}}$ and oxygen antisite, $\mathrm{O}_{\mathrm{Zn}}$ ). It is known that the relative content of donor and acceptors influences the semiconductor properties of $\mathrm{ZnO}^{25}$

Scheme 1 and Table 1 show the various defects level emissions for the deconvoluted peaks (a to f) of the PL spectra (Fig. 3c). The origin of the PL spectra is complicated, which is due to the fact that PL is mostly related to $\mathrm{V}_{\mathrm{O}}$ and/or $\mathrm{Zn}_{\mathrm{i}}$. As mentioned above, the Ref and EB-Z100 samples only exhibit UV emission (peak a), which is due to that free excitons (FX, $0.06 \mathrm{eV}$ 


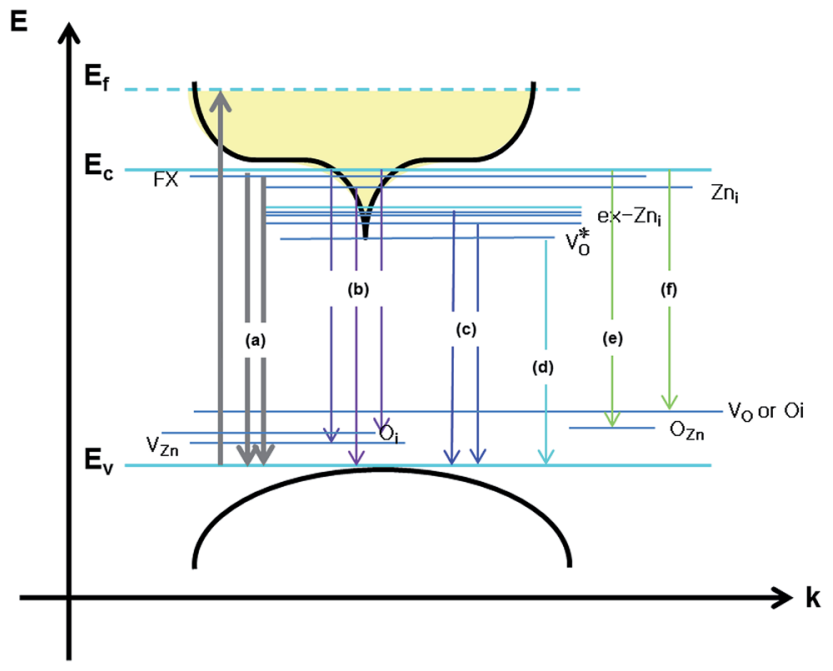

Scheme 1 Schematic diagram of the energy band structures of EB$\mathrm{ZnO}$ and photoluminescence mechanism of EB-ZnO corresponding to the data in Table 1.

below the $\mathrm{CB}$ ) recombine with holes in the $\mathrm{VB} .{ }^{26}$ With an increase in the absorption dose, the PL spectra display visible region broadening. The violet emission (peak b) displayed in all the samples is probably attributed to (1) $\mathrm{Zn}_{\mathrm{i}}$ (about $0.22 \mathrm{eV}$ below the $\mathrm{CB}) \rightarrow$ VB transition or (2) $\mathrm{CB} \rightarrow$ single ionized $\mathrm{V}_{\mathrm{Zn}}$ (about $0.3 \mathrm{eV}$ above the $\mathrm{VB}$ ) or (3) $\mathrm{CB} \rightarrow \mathrm{O}_{\mathrm{i}}$ (about $0.4 \mathrm{eV}$ above the VB). ${ }^{25-27}$ The blue emission (peak c) of EB-Z300 and EB-Z500 is due to ex- $\mathrm{Zn}_{\mathrm{i}}$, which is the extended states of $\mathrm{Zn}_{\mathrm{i}}$ from 0.54 to $0.64 \mathrm{eV}$ below the CB. ${ }^{26,27}$ This can be correlated to the additional Zn 1p peaks of EB-Z300 and EB-Z500 (the shaded area, inset Fig. 2), where the shaded area of EB-Z500 is significant (inset Fig. 2). For the EB-ZnO samples, the sky blue emission (peak d) results from the process $\left(\mathrm{V}_{\mathrm{O}}^{*} \rightarrow \mathrm{V}_{\mathrm{O}}^{+}+\mathrm{e}^{-}\right.$, below the $\mathrm{CB}$ ) in the grain boundary. ${ }^{26}$ The increase in the content of $\mathrm{O}_{\mathrm{b}}$ for the EB-ZnO samples is evidence of this emission. For only the Ref sample, electron transition from the $\mathrm{CB}$ to $\mathrm{O}_{\mathrm{Zn}}$ occurs (peak e). ${ }^{28}$ The green emission (peak f) of EB-Z300 and EB-500 is due to two possibilities: (1) $\mathrm{CB} \rightarrow \mathrm{O}_{\mathrm{i}}$ (about $1.09 \mathrm{eV}$ above the VB) or (2) trap state emissions attributed to the single ionized $\mathrm{V}_{\mathrm{O}}$ (about $0.90 \mathrm{eV}$ above the VB). ${ }^{27}$ The PL spectra of EB-Z100 includes two subpeaks ( $b$ and $d$ ) related to donor defects $\left(\mathrm{Zn}_{\mathrm{i}}\right.$ and $\left.\mathrm{V}_{\mathrm{O}}^{*}\right)$, whereas that of EB-Z300 and EB-Z500 significantly include additional contents (lines $\mathrm{d}$ and $\mathrm{f}$ ) related to both donor and acceptor defects $\left(\mathrm{V}_{\mathrm{Zn}}, \mathrm{O}_{\mathrm{i}}\right.$ and $\left.\mathrm{V}_{\mathrm{O}}\right)$. The origin of the PL emission does not seem to clearly correlate with the intrinsic or extrinsic defects due to the extremely complicated defect energy level. However, the presence of ex- $\mathrm{Zn}_{\mathrm{i}}$ and $\mathrm{V}_{\mathrm{O}}$ is supported by the XPS results, which indicates that oxygen vacancies and $\mathrm{Zn}$ interstitial are dependent on the irradiation dose.

\section{Electronic properties}

To observe the change in energy levels of the EB-ZnO samples, we carried out ultraviolet photoelectron spectroscopy (UPS) measurements (Fig. 4a). Fig. 4 b and Table 2 exhibit the energy levels extracted from the UPS results. The work function (W.F, $\varphi$ ) is determined by the distance between the secondary electron edge at high binding energy and HeI energy $=21.2 \mathrm{eV}$ (the left panel in Fig. 4a). The valence band maximum (VBM) was calculated from the onset to the $E_{\mathrm{f}}$ at the low binding energy region (the right panel in Fig. 4a). The conduction band minimum (CBM) was estimated from the VBM and $E_{\mathrm{g}}$ (extracted from the Tauc plot). The Ref samples show a W.F of about $4.12 \mathrm{eV}$, which is similar with that of previously reported sol-gel $\mathrm{ZnO},{ }^{29}$ but an $E_{\mathrm{f}}$ slightly above the $\mathrm{CB}$ is observed in our study. With the increase in irradiation dose from 100, 300 to $500 \mathrm{kGy}$, the W.F decreases from 3.75, 3.55 to $2.99 \mathrm{eV}$, respectively. As mentioned for the bandgap widening of the EB-ZnO samples, the $E_{\mathrm{f}}$ of EB-ZnO samples shifts above the CB (i.e., the EB-ZnO samples are degenerated) from the UPS data. Given both optical properties (the red shift of PL spectra and bandgap broadening) and UPS data, the EB-ZnO samples seem to be heavily n-type doped $\mathrm{ZnO}$. Although $\mathrm{N}$-doped $\mathrm{ZnO}$ with $\mathrm{N}-\mathrm{Zn}$ bonds is known as p-type, in our study, n-type doping of EB-ZnO can be explained by (1) the zinc interstitial and oxygen vacancy as the donor result in band tails, which merge with the CB and cause band broadening, ${ }^{23}$ or (2) N-C bonds, such as amine groups,
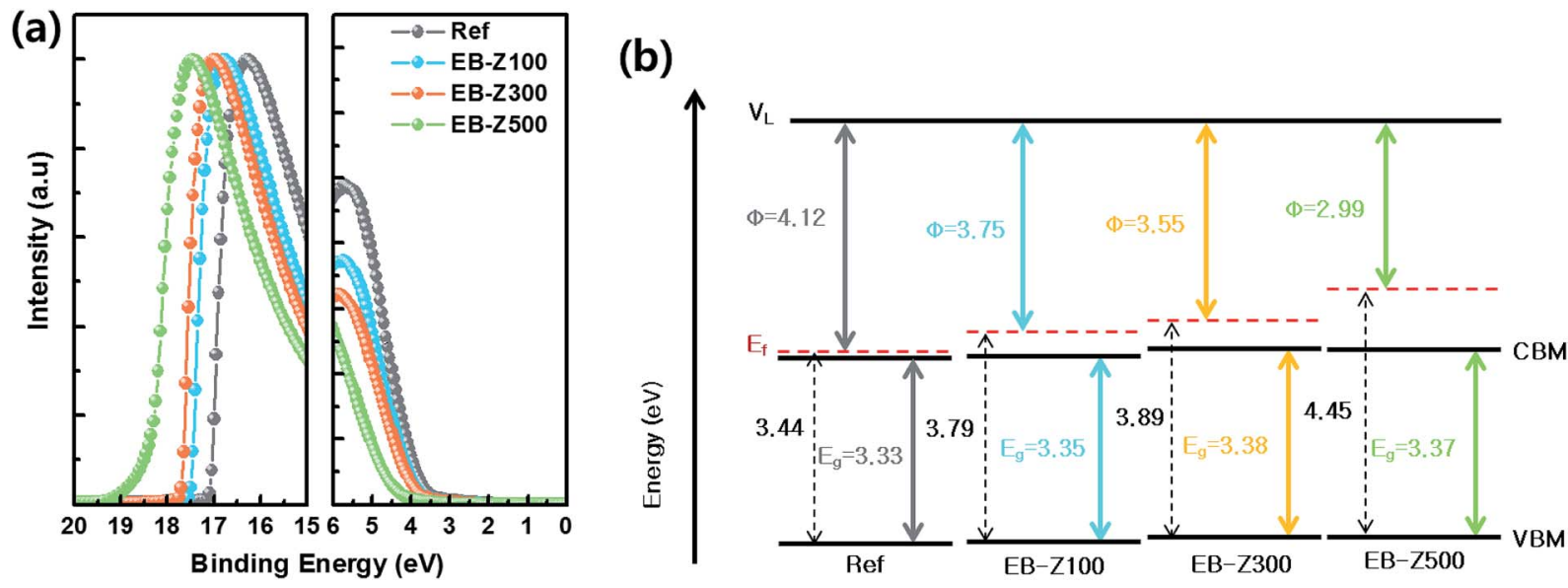

Fig. 4 (a) UPS data and (b) corresponding energy diagram of Ref, EB-Z100, EB-Z300 and EB-Z500. 
adsorbed on the surface can influence the reduction of W.F due to the interfacial dipole, similarly to the previously reported result. ${ }^{30}$ Unfortunately, in our study, the electron mobility and hole measurement of the Ref and EB-ZnO samples could not be measured probably due to the highly resistive films.

\section{Photovoltaic properties}

The photovoltaic properties of the samples were investigated with the device structure of ITO/EB-ZnO/PTB7-Th: $\mathrm{PC}_{71} \mathrm{BM} /$ $\mathrm{MoO}_{3} / \mathrm{Ag}$. The $J-V$ characteristic in a single batch and the average of photovoltaic performance parameters are shown in Fig. 5a-c and Table 3. For the Ref samples, the open circuit voltage $\left(V_{\mathrm{oc}}\right)$, short circuit current density $\left(J_{\mathrm{sc}}\right)$, fill factor $(\mathrm{FF})$ and PCE values were $0.79 \mathrm{~V}, 15.92 \mathrm{~mA} \mathrm{~cm}^{-2}, 64.3 \%$ and $8.05 \%$, respectively. When EB-Z100 and EB-Z300 were used, the PCE was significantly enhanced, and the device with EB-Z100 shows the best performance with an FF of $71.8 \%$ and PCE of $9.36 \%$ (increase of 13\%). From the modified W.F, we expected that EB$\mathbf{Z 5 0 0}$ would show the best results because the W.F of the samples decreases with the increase in irradiation dose. Interestingly, EB-Z500 shows the lowest PCE and widest distribution of PCE. The external quantum efficiency (EQE) of the same devices is shown in Fig. $5 \mathrm{~d}$. The measured $J_{\mathrm{sc}}$ is less than the value calculated from the EQE data (the error is less than 10\%). This discrepancy can be due to the difference in illumination conditions. $^{31}$

Given the average performance parameters, there is no difference in $V_{\mathrm{oc}}$, whereas the tendency of FF is the same as that of PCE. The $V_{\text {oc }}$ is mainly determined by the energy level difference between the highest occupied molecular orbital (HOMO) of the donor and the lowest unoccupied molecular orbital (LUMO) of the acceptor and the work function difference of two metals. However, our result shows that the $V_{\text {oc }}$ does not change, which is because the band bending between the low conductivity $\mathrm{ZnO}$ and organic layers may not be significant. From Table 3 and Fig. 5e, the series resistance $\left(R_{\mathrm{s}}\right)$ for the devices with Ref and EB-Z100 is similar, whereas $R_{\mathrm{S}}$ for the device with EB-Z300 and EB-Z500 increases, and the shunt resistance $\left(R_{\mathrm{sh}}\right)$ for the device with EB-Z100 increases, whereas $R_{\text {sh }}$ for the devices with EB-Z300 and EB-Z500 decreases; and for all the samples, there is a difference in $R_{\text {sh }}$ but it is not significantly large because it is not one order of magnitude, except for EB-Z100. The reduction in $R_{\mathrm{S}}$ and increase in $R_{\mathrm{sh}}$ for EB-Z100 may reduce the leakage current and charge transport barrier and suppress the charge recombination, ${ }^{32}$ thus resulting in high FF and PCEs. (a)

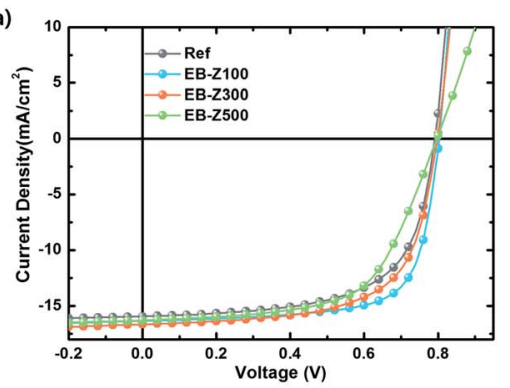

(d)

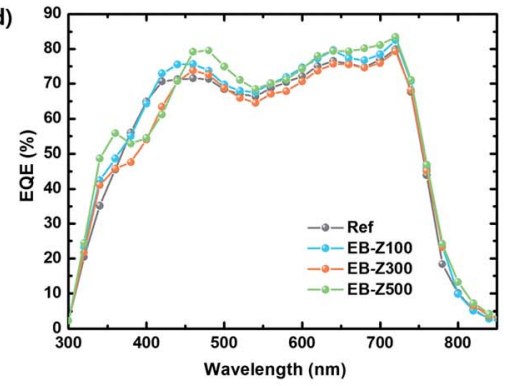

(b)
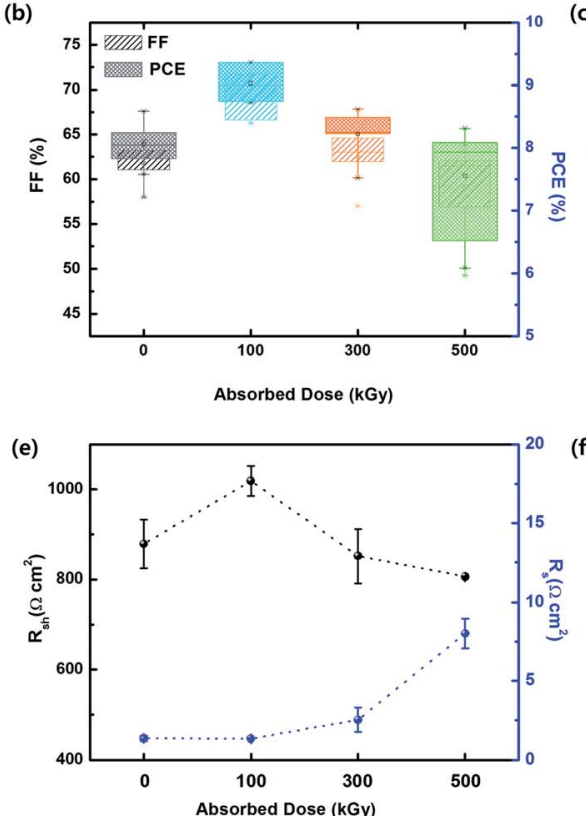

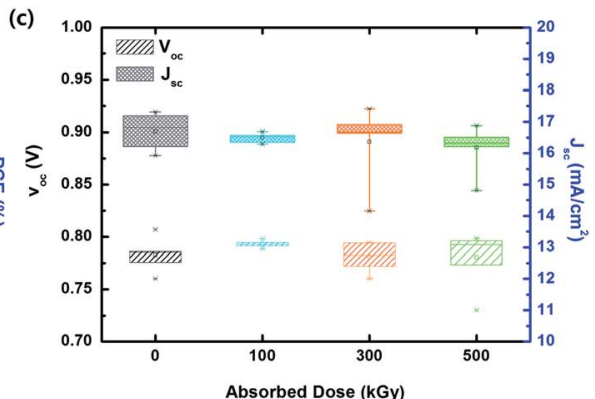

(f)

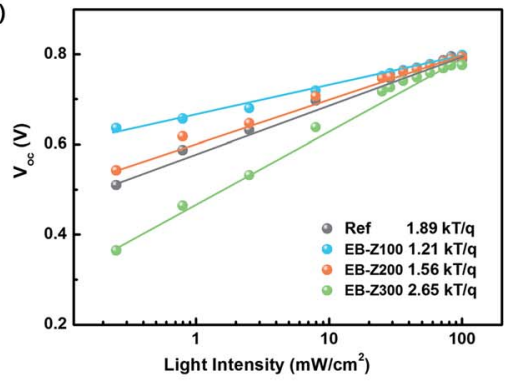

Fig. 5 (a) J-V curve, (b) variation in FF and PCE, (c) variation in $V_{\mathrm{oc}}$ and $J_{\mathrm{sc}}$, (d) corresponding EQE data, (e) $R_{\mathrm{s}}$ and $R_{\mathrm{sh}}$, and (f) $V_{\mathrm{oc}}$ dependence on $P_{\text {light }}$ for the PSCs based on ITO/Ref and EB-ZnO/PTB7-Th:PC ${ }_{71} \mathrm{BM}_{\mathrm{MOO}} / \mathrm{Ag}$.

Table 3 The photovoltaic parameters of the devices shown in Fig. 5a and measurements from 8 PSC devices based on ITO/Ref and $\mathrm{EB}-\mathrm{ZnO} / \mathrm{PTB} 7-\mathrm{Th}: \mathrm{PC}_{71} \mathrm{BM} / \mathrm{MoO}_{3} / \mathrm{Ag}$

\begin{tabular}{|c|c|c|c|c|c|c|c|}
\hline Sample & $V_{\mathrm{oc}}(\mathrm{V})$ & $J_{\mathrm{sc}}\left(\mathrm{mA} \mathrm{cm}^{-2}\right)$ & $\mathrm{FF}(\%)$ & PCE $(\%)$ & $\mathrm{EQE} J_{\mathrm{sc}}\left(\mathrm{mA} \mathrm{cm}{ }^{-2}\right)$ & $R_{\mathrm{s}}\left(\Omega \mathrm{cm}^{2}\right)$ & $R_{\mathrm{sh}}\left(\Omega \mathrm{cm}^{2}\right)$ \\
\hline Ref & $0.79(0.78 \pm 0.02)$ & $15.92(16.69 \pm 0.6)$ & $64.3(61.8 \pm 2.4)$ & $8.05(7.93 \pm 0.3)$ & 17.50 & $1.35 \pm 0.15$ & $878 \pm 54$ \\
\hline EB-Z100 & $0.80(0.79 \pm 0.01)$ & $16.35(16.49 \pm 0.2)$ & $71.8(69.1 \pm 2.4)$ & $9.36(8.93 \pm 0.3)$ & 18.03 & $1.33 \pm 0.06$ & $1018 \pm 33$ \\
\hline EB-Z500 & $0.80(0.78 \pm 0.03)$ & $16.27(16.17 \pm 0.7)$ & $61.2(61.1 \pm 5.4)$ & $7.93(7.47 \pm 0.9)$ & 18.23 & $8.00 \pm 0.95$ & $806 \pm 0.2$ \\
\hline
\end{tabular}


The results for EB-Z100 can be ascribed to (1) energetically favorable electron transporting ${ }^{29}$ from $\mathrm{PC}_{71} \mathrm{BM}$ to $\mathbf{E B}-\mathbf{Z 1 0 0}$ due to the energy level offset between the LUMO of $\mathrm{PC}_{71} \mathrm{BM}$ (about $3.9 \mathrm{eV}$ ) and up shifted $E_{\mathrm{f}}(\mathrm{W} . \mathrm{F}=3.75 \mathrm{eV})$, which is attributed to $\mathrm{Zn}_{\mathrm{i}}$ and $\mathrm{V}_{\mathrm{O}}$, (2) smoother surface (root mean square (RMS): $0.698 \mathrm{~nm}$ ), which enables good contact with the active layer, and (3) reduced surface hydroxyl groups, which can trap electrons and holes. Although EB-Z300 shows a lower $R_{\mathrm{sh}}$ and higher $R_{\mathrm{S}}$, its PCE and FF is better, compared with that of the Ref sample, and its results are complicated due to its lower work function, slightly rough surface (rms: $0.943 \mathrm{~nm}$ ) and various defects. EBZ500 shows the worst result with the largest $R_{\mathrm{S}}$ and lowest $R_{\mathrm{sh}}$ which can result from its roughest surface (rms: $3.939 \mathrm{~nm}$ ) inducing bad contacts with the active layer. Despite the reduced surface hydroxyl groups of EB-Z500, another reason for its poor results can be that it is too heavily doped $\mathrm{ZnO}$ due to the increase in $\mathrm{Zn}_{\mathrm{i}}$, which leads to an increase in charge recombination. In our study, $\mathrm{Zn}_{\mathrm{i}}$ and $\mathrm{V}_{\mathrm{O}}$ resulted in appropriately degenerated (doped) $\mathrm{ZnO}$ for better energy transfer in solar cells below 500 kGy. The correlation between defects and device performance is very complicated due to simultaneous presence of various defects.

To understand the nature of charge carrier recombination, we investigated the light intensity $\left(P_{\text {light }}\right)$ dependence of $V_{\text {oc }}$, which enables bimolecular and trap-assisted recombination ${ }^{32,33}$ to be distinguished in Fig. $5 \mathrm{~d}$. The slope (S) of $V_{\mathrm{oc}}$ versus the logarithm of $P_{\text {light }}$ indicates the presence of trap-assist recombination; and the $S$ value is $1.89,1.21,1.56$ and $2.65 \mathrm{kT} \mathrm{q}^{-1}$ for Ref, EB-Z100, EB-Z300 and EB-Z500, respectively. This trend is not exactly matched to the trend of $R_{\mathrm{sh}}$; however, the lowest $\mathrm{S}$ of EB-Z100 (S nearly equal to $\mathrm{kT} \mathrm{q}^{-1}$ ) is consistent with the lowest $R_{\mathrm{s}}$ and this result contributes to the dominant bimolecular recombination, whereas the highest $\mathrm{S}$ of EB-Z500 is also consistent with the highest $R_{\mathrm{sh}}$, thus trap-assisted recombination is expected to be dominant. Although the trend of resistance $\left(R_{\mathrm{S}}\right.$ and $\left.R_{\mathrm{sh}}\right)$ of EB-Z300 is not matched to the FF and PCEs, its smaller $S$, which indicates the reduction of charge recombination, can explain the PCE value. Therefore, EB-ZnO as a CIL is beneficial to reduce charge recombination in polymer solar cells.

\section{Conclusions}

In conclusion, we demonstrated an efficient and simple method to obtain modified sol-gel ZnO films by irradiating the sol-gel ZnO precursor solution with an electron beam. The photovoltaic performance of the device based on EB-ZnO is dependent on irradiation dose. The enhancement in the photovoltaic performance of the device based on EB-ZnO is mainly due to (1) lower work function, which is attributed to degenerated n-type $\mathrm{ZnO}$ by donors such as $\mathrm{Zn}_{\mathrm{i}}$ and $\mathrm{V}_{\mathrm{O}}$, (2) reduced surface hydroxyl groups, and (3) smooth surface, which lead to efficient electron transfer and low leakage current. As a result, the PCE of the device with EB-Z100 achieved $9.36 \%$ with a $16 \%$ increment, compared with $8.05 \%$ for Ref. Most importantly, we demonstrate the feasibility of enhancing the efficiency of inverted polymer solar cells by using modified sol-gel ZnO films, which are obtained by irradiating sol-gel $\mathrm{ZnO}$ solutions with an electron beam, and that this approach can be a simple method for manufacturing modified sol-gel ZnO.

\section{Acknowledgements}

The acknowledgements come at the end of an article after the conclusions and before the notes and references. This work (2017M2A2A601019867) was supported by the National Research Foundation of Korea (NRF) grants funded by the Ministry of Science, ICT \& Future Planning. We thank the Korea Institute of Science and Technology (KIST) for UPS and XPS data.

\section{References}

1 Q. Wan, X. Guo, Z. Wang, W. Li, B. Guo, W. Ma, M. Zhang and Y. Li, Adv. Funct. Mater., 2016, 26, 6635.

2 Y. Liu, J. Zhao, Z. Li, C. Mu, W. Ma, H. Hu, K. Jiang, H. Lin, H. Ade and H. Yan, Nat. Commun., 2014, 5, 5293.

3 S. Holliday, R. S. Ashraf, A. Wadsworth, D. Baran, S. A. Yousaf, C. B. Nielsen, C. Tan, S. D. Dimitrov, Z. Shang and N. Gasparini, Nat. Commun., 2016, 7, 11585.

4 Y. Lin, J. Wang, Z. G. Zhang, H. Bai, Y. Li, D. Zhu and X. Zhan, Adv. Mater., 2015, 27, 1170.

5 H. Zhou, Y. Zhang, C. K. Mai, S. D. Collins, G. C. Bazan, T. Q. Nguyen and A. J. Heeger, Adv. Mater., 2015, 27, 1767.

6 J. Huang, C. Z. Li, C. C. Chueh, S. Q. Liu, J. S. Yu and A. K. Y. Jen, Adv. Energy Mater., 2015, 5, 1500406.

7 B. Walker, H. Choi and J. Kim, Curr. Appl. Phys., 2017, 17, 370.

8 R. Kang, S. H. Oh and D. Y. Kim, ACS Appl. Mater. Interfaces, 2014, 6, 6227.

9 I. Etxebarria, A. Guerrero, J. Albero, J. G. Garcia-Belmonte, E. Palomares and R. Pacios, Org. Electron., 2014, 15, 2756.

10 S. Nho, G. Baek, S. Park, B. Lee, M. Cha, D. Lim, J. Seo, S. H. Oh, M. S. Song and S. Cho, Energy Environ. Sci., 2016, 9, 240.

11 W.-Y. Jin, R.-T. Ginting, S.-H. Jin and J.-W. Kang, J. Mater. Chem. A, 2016, 4, 3784.

12 Z. Liang, Q. Zhang, L. Jiang and G. Cao, Energy Environ. Sci., $2015,8,3442$.

13 B. I. Kharisov, O. V. Kharissova and U. Mendez, Radiation Synthesis of Materials and Compounds, CRC Press, 2013, ch. 4, pp. 81-83.

14 N. S. Kown, C. H. Jung and S. I. Na, Org. Electron., 2016, 34, 67.

15 K. B. Sapnar, V. N. Bhoraskar, S. D. Dhole, L. A. Ghule and K. M. Garadkar, Effects of $6 \mathrm{MeV}$ Electron Irradiation on $\mathrm{ZnO}$ Nanoparticles Synthesized by Microwave Method. Proceedings of 2011 Particle Accelerator Conference, New York, NY, USA, 2011, pp. 2166-2168.

16 J. S. Bhat, A. S. Patil, N. Swami, B. G. Mulimani, B. R. Gayathri, N. G. Deshpande, G. H. Kim, M. S. Seo and Y. P. Lee, J. Appl. Phys., 2010, 108, 043513.

17 Y. Sun, J. H. Seo, C. J. Takacs, J. Seifter and A. J. Heeger, Adv. Mater., 2011, 23, 1679. 
18 Q. Zhu, C. Xie, H. Li, C. Yang, S. Zhang and D. Zeng, J. Mater. Chem. C, 2014, 2, 4566.

19 F. Kayaci, S. Vempati, I. Donmez, N. Biyikli and T. Uyar, Nanoscale, 2014, 6, 10224.

20 F. Guo, W. Shi, W. Guan and Y. Liu, Sep. Purif. Technol., 2017, 173, 295.

21 Y. Yoon, M. Kwon, B. C. Lee and J. W. Kang, J. Adv. Oxid. Technol., 2012, 15, 301.

22 Y. J. Choi, K. M. Kang and H. H. Park, Sol. Energy Mater. Sol. Cells, 2015, 132, 403.

23 H. P. He, Z. Wang, H. F. Duan and Z. Z. Ye, Phys. Chem. Chem. Phys., 2015, 17, 17552.

24 T. Makino, Y. Segawa, S. Yoshida, A. Tsukazaki, A. Ohtomo and M. G. Kawasaki, Appl. Phys. Lett., 2004, 85, 759.

25 K. Lim, M. A. A. Hamid, R. Shamsudin, N. H. Al-Hardan, I. Mansor and W. Chiu, Materials, 2016, 9, 300.

26 F. Kayaci, S. Vempati, I. Donmez, N. Biyikli and T. Uyar, Nanoscale, 2014, 6, 10224.

27 S. Vempati, J. Mitra and P. Dawson, Nano Res. Lett., 2012, 7, 470.
28 L. X. Zhang, J. H. Zhao, H. Q. Lu, L. Li, J. F. Zheng, J. Zhang, H. Li and Z. P. Zhu, Sens. Actuators, B, 2012, 171-172, 1101.

29 L. Zuo, S. Zhang, S. Dai and H. Chen, RSC Adv., 2015, 5, 49369.

30 Y. Zhou, C. Fuentes-Hernandez, J. Shim, J. Meyer, A. J. Giordano, H. Li, P. Winget, T. Papadopoulos, H. Cheun, J. Kim, M. Fenoll and A. Dindar, Science, 2012, $336,327$.

31 E. Zimmermann, P. Ehrenreich, T. Pfadler, J. A. Dorman, J. Weickert and L. Schmidt-Mende, Nat. Photonics, 2014, 8, 669.

32 J. S. Yeo, M. J. Kang, Y. S. Jung, R. Kang, S. H. Lee, Y. J. Heo, S. H. Jin, D. Y. Kim and S. I. Na, Nano Energy, 2016, 21, 26.

33 C. M. Proctor and T.-Q. Nguyen, Appl. Phys. Lett., 2015, 106, 083301.

34 X. Zhang, J. Qin, Y. Xue, P. Yu, B. Zhang, L. Wang and R. Liu, Sci. Rep., 2014, 4, 4596.

35 Z. Liang, Q. Zhang, L. Jiang and G. Cao, Energy Environ. Sci., 2015, 8, 3442-3476. 